\title{
3 \\ Combined Urban and Rural Models for Integrated River Basin Management
}

\section{Arne Klawitter and Manfred Ostrowski}

Traditionally, urban and rural hydrology consider rainfall runoff processes very differently. Usually they are modeled independently, and linked, if at all, by data transfer interfaces. Only a few meso-scale models are known that are capable of modeling both urban and rural catchments simultaneously at a high spatial resolution; and, even in these, detailed interactions between the different hydrologic sub-systems are hardly taken into account. In the field of urban hydrology, successful attempts have been made to model sewer systems including wastewater treatment plants (WWTP) and receiving water bodies. However, pollutants from rural areas are mostly neglected when modeling the water quality of receiving water bodies. The complexity of an integrated model, taking into account rural and urban systems, as well as their interactions, is one of the major reasons for the lack of such a model. However, such models are urgently needed for the realisation of the EUWater Framework Directives (EU-WFD, 2000) which aims at achieving ecological improvements.

In this chapter, an approach is described, which takes into account the interaction of urban and rural hydrology by a 2-layer modeling system. For this approach, two existing models have been modified and combined with pre-defined points of interaction. The main goal of the development was improved flow peak simulation in streams loaded with multiple combined sewer overflows from several sewer networks. Criteria for water quality in

Klawitter, A. and M. Ostrowski. 2008. "Combined Urban and Rural Models for Integrated River Basin Management." Journal of Water Management Modeling R228-03. doi: 10.14796/JWMM.R228-03.

(C) CHI 2008 www.chijournal.org ISSN: 2292-6062 (Formerly in Reliable Modeling of Urban Water Systems. ISBN: 978-0-9808853-0-9) 
the receiving water bodies are neglected in this discussion, but were kept in mind by the authors for further development of the integrated model system.

The models chosen are a highly distributed deterministic GIS-based hydrological grid-model for rural areas as well as a semi-distributed deterministic hydrological pollution load model that is based on hydrologically similar units for urban areas, respectively. At this stage, the urban hydrologic model also contains a module for pollution transport and a simple component for the hydraulic representation of a WWTP.

In the 2-layer approach, the two layers represent the rural and the urban systems respectively. Within each time step, both layers are simulated simultaneously allowing for the consideration of feedback processes. Concerning the modification of surface and subsurface flow patterns in urban areas, further assumptions had to be made. For example, the interflow process underneath urban areas is "deactivated" in the corresponding grids of the rural model; hence only vertical underground flow processes in the soil zone are considered. Overland flow from rural areas into an urban settlement will be processed according to the flow patterns given in the urban system .

The model is designed to handle any degree of urbanisation in a mesoscale catchment up to $1000 \mathrm{~km}^{2}$. It can account for urban areas located outside the rural catchment, but draining into the rural catchment boundaries; and for urban areas located inside the rural catchment, but draining beyond the boundaries of the rural catchment. The model's functionality will be demonstrated by means of a case study .

\subsection{Methodology}

To achieve the above mentioned goal, two existing models were modified and integrated into one system based on a 2-layer GIS. The first model, initially developed by Lempert (2000), is a highly distributed deterministic GIS-based hydrological grid-model for rural areas. This model can consider urban areas in a very simple integrated manner only. The second one is a semi-distributed deterministic hydrological pollution load model (Muschalla $\&$ Ostrowski, 2006), based on hydrologically similar units, for urban areas. The 2-layer modeling approach provides the continuous interaction within each time step between the rural hydrologic and the more hydraulically defined urban sub-systems with a special integration approach to account for different temporal resolutions. 
Outflows from the urban system, such as combined sewer overflows or effluent from waste water treatment plants, are hydraulic and pollutant loads for the receiving water body. Recently, the European water framework directives (EU-WFD, 2000) were introduced, asking for the retransformation of all surface water bodies into a good ecologic status. Initially, emissions from urban drainage systems were considered negligible, but after several years of analysis it became evident that hydraulic stress can cause severe drift of organisms and bed erosion. It became questionable whether the formerly customary aggregated modeling of urban overflows was sufficiently accurate to identify critical local situations and related measures for improvement.

The coupled 2-layer model was applied to a real world case study for which a river basin management plan has to be developed until 2007. It could be shown that the new approach has several advantages over traditional aggregated modeling approaches with respect to overall accuracy and local critical conditions.

\subsection{Model Description}

In the following section both the rural and the urban model are described briefly. The main model structures as well as the most important algorithms are mentioned. However, it must be pointed out that any other two models with similar spatial representation could have been used for the implementation of the 2-layer approach. Emphasis is therefore placed on the general description of model coupling and not on the description of the model algorithms and parameters. A full description of the 2-layer approach is given by Klawitter (2006).

\subsubsection{Climatic Boundary Conditions}

Climatic boundary conditions for both sub-models are defined by precipitation, potential evapotranspiration and temperature. The spatial distribution of rain can be considered by means of Thiessen-polygons, by different inverse distance methods or simply by an elevation dependent method. Actual evapotranspiration is divided into evaporation from interception storage, evaporation from the upper soil layer and transpiration from the root zone. Temperature is used to trigger snow simulation, which is based on the combined temperature-index/snow-compaction method, as 
adopted to German conditions by Knauf (1975). The areal distribution of temperature can be considered in the snow simulation.

\subsubsection{Model for Rural Areas}

The distributed deterministic grid model for rural areas was coupled with the GIS idrisi (Eastman, 1999) also used to present areal model output variables. A preceding analysis of a digital elevation model (DEM) is the topographic basis for the model. The flow paths on the surface and the river network (Figure 3.1, on the left) are determined by the D8-method (O'Callaghan and Mark, 1984) identifying also natural channels. The model requires GIS maps with information on soils and land use. The soil column is represented by a three layer system consisting of an infiltration zone, a root zone and a transient zone, each zone having a user defined depth. The soil in each zone is defined by welting point, field capacity, total pore volume, maximum infiltration capacity and hydraulic conductivity.

Canopy interception is modeled by an approach similar to the Rutter interception model. Soil moisture modeling is based on the work of Ostrowski (1982), it calculates soil moisture within the three soil layers, as well as related processes such as effective runoff, interflow, macropore flow, percolation into the groundwater, and capillary rise. This soil moisture submodel considers backwater effects due to soil saturation and thus accounts for both hortonian and saturation overland flow (Lempert, 1997). Overland flow is then routed from grid to grid by the kinematic wave approach. As soon as a natural channel is reached, the overland flow is routed in this channel, together with interflow and baseflow using again the kinematic wave approach. For both overland flow and channel flow, a non-linear reservoir approach is used to solve the kinematic wave equation. Required model parameter beside slope (derived from the DEM) is a land-usedependent Manning coefficient.

\subsubsection{Model for Urban Areas}

The semi-distributed deterministic urban rainfall runoff and pollution load model is based on hydrological concepts and supported by a graphical user interface. An example of a systematic flow scheme is shown for the case study in Figure 3.1 on the right. The elements of a system flow scheme are urban catchments, sewers or open channels, retention basins, stormwater overflow structures and wastewater treatment plants. At this stage, the urban 
hydrologic model already contains a module for pollution transport, which however is not further discussed in this chapter.

Runoff is generated after surface wetting and a gradient-dependent depression storage volume is exceeded. Runoff is then routed to the outlet by a parallel cascade of linear reservoirs. As model input, the surface runoff time is needed to compute the retention constants for the cascades. Depression storage is recovered by the potential evaporation rate after a rainstorm.
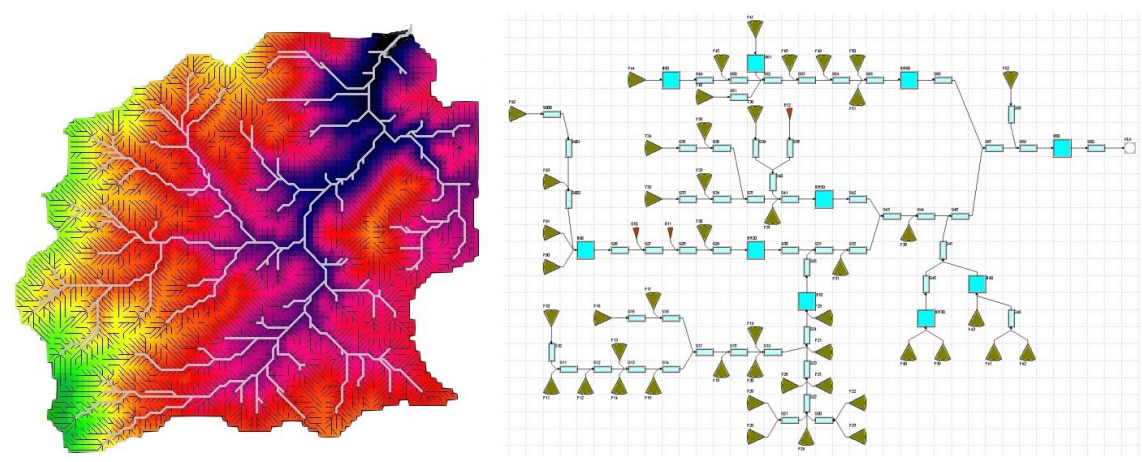

Figure 3.1 Left: Structure of the grid model for rural areas; Right: Structure of the urban model for urban areas.

Transport in sewers and channels is based on the Kalinin-Miljukov algorithm (Rosemann \& Vredal, 1970) and computes stormwater and dry weather runoff separately. Retention basins and stormwater overflows can be modeled in several degrees of detail. Retention effects of wastewater treatment plants are modeled by linear reservoirs.

\subsubsection{Coupling the Urban with the Rural Model}

The coupling of the two standalone models is achieved by a 2-layer approach, which assigns the sub-models to two layers, for which points of interaction can be defined. This approach is shown in Figure 3.2. Within each time step, both models calculate discharges, runoff, etc. and interchange values at the predefined points of interaction. As indicated in Figure 3.2, the urban model can be included numerous times within the rural model, giving the chance of multiple urban modeling within the 2-layer model approach. 
Elementary units of the urban system are geo-referenced by means of a GIS map, to make their location known to the rural catchment. From the elevations of the grid points in the rural model, the mean elevation as well as a mean precipitation value for the urban elementary units can be calculated beforehand. Depending on the mean elevation of an urban unit, the height dependent temperature is calculated. A constant value of $1^{\circ} \mathrm{C}$ is added to urban temperature values, to account for urban warming effects.

As indicated in Figure 3.2, discharges from urban areas, e.g. from the wastewater treatment plants, retention basins etc., are added to a predefined channel grid cell within the rural model and consequently routed through the river channel together with natural flow components. However, backwater effects into the stormwater drainage systems cannot be computed yet.

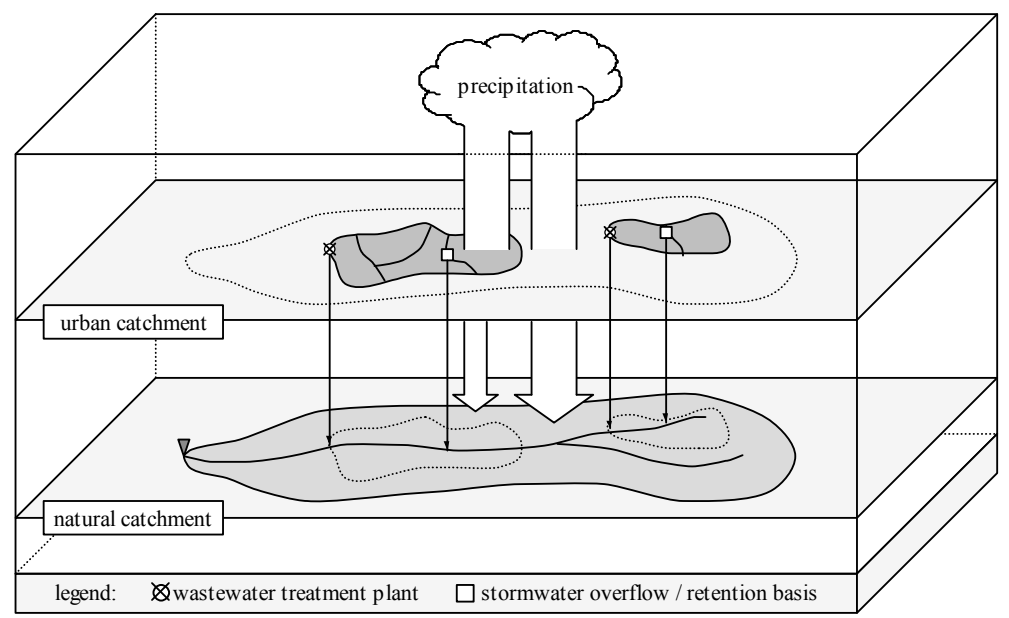

Figure 3.2 Two-layer approach - the urban catchment layer on top, the natural catchment layer below.

The calculations in the rural model are carried out grid by grid, following a predefined sequence derived from the natural topography of the catchment. When a grid cell is reached where an overlaying urban area exists, some changes occur: Depending on the degree of impermeability of the urban area, the precipitation volume is apportioned between the urban and the rural area. This results in a lower soil moisture and a reduced groundwater recharge rate underneath urban areas. Because sewer systems, basements or other underground structures act as obstacles for subsurface flow, lateral 
flow components such as interflow are "deactivated" underneath urban settlements. As soon as excess rainfall on pervious urban areas occurs, it is not processed according to the flow path of the natural topography, but is assumed to contribute to the flow of the urban catchment. This is considered a point of interaction where the natural catchment influences the runoff in urban catchments.

Even though urban catchments are geo-referenced, at this point no georeferencing of the sewer system exists in the model. Hence, infiltration into, or exfiltration out of, the sewer system are not taken into account. Because it is virtually impossible to exactly quantify these effects, neglecting the processes of interaction between sewer system and soil matrix seems to be reasonable at this modeling scale.

The model is designed to handle any degree of urbanisation. It also accounts for urban areas being situated outside the rural catchment but draining into the rural catchment boundaries; and urban areas being located within the rural catchment, but draining beyond the catchment boundaries.

\subsubsection{Code Description and Computational Requirements}

The model code is written in Fortran95 and built in a modular manner. Further components could be added easily in the future.

Despite the model coupling, model run times are comparatively low due to the analytical solutions of the implemented model algorithms. For example: to simulate a period of one day, using a temporal resolution of 5 minutes and 55000 grid cells within the rural model (see Modau test case example) a $2000 \mathrm{MHz}-$ Processor needs approximately 5 minutes. Simulation times can be reduced significantly when reducing the spatial and or the temporal resolution of the grid model.

Special hardware is not required. However, memory of $1 \mathrm{~GB}$ and a 2000 MHz-Processor are recommended.

\subsection{The River Modau Test Case}

\subsubsection{The Upper Modau River Catchment}

After testing the model on several hypothetical case studies, the 2-layer model was finally applied to a real world case study, the upper Modau river catchment, which is shown in Figure 3.3. The basin has a catchment area of 
$90 \mathrm{~km}^{2}$ with $15 \%$ impervious area. The urban drainage systems consist of four wastewater treatment plants and 69 combined sewer overflows. A retention reservoir provides flood protection. The hydrological data base consists of three daily rain gauges, one neighboring rainfall recorder, a climatological station and a flow gauge at the end of the catchment. Geographical data were available as a 40x40 m DEM and digital land use and soil maps on a 1:50.000 scale.

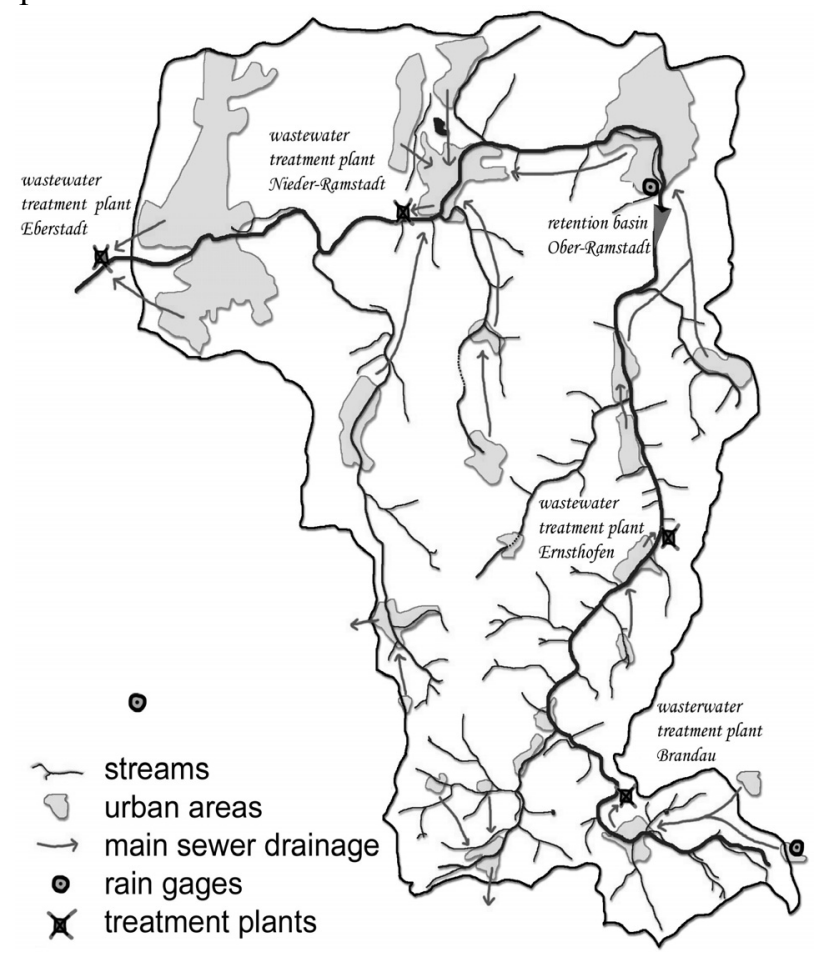

Figure 3.3 Schematic view of the upper Modau River.

\subsubsection{Model Calibration and Verification}

The model was calibrated for a longer rainy period and then verified for a shorter period. The calibration results for one rainfall event are exemplarily given in Figure 3.4. in graphical form. Table 3.1 shows calibration and 
verification results with goodness-of-fit criteria being the correlation coefficient, the Nash and Sutcliffe criterion and mass balance error.

Despite some limitations concerning continuous rainfall information the results can be considered as excellent. Goodness-of-fit by far exceeds simulation runs based on a semi-distributed model for the Upper River Modau (Ostrowski et al, 2005).

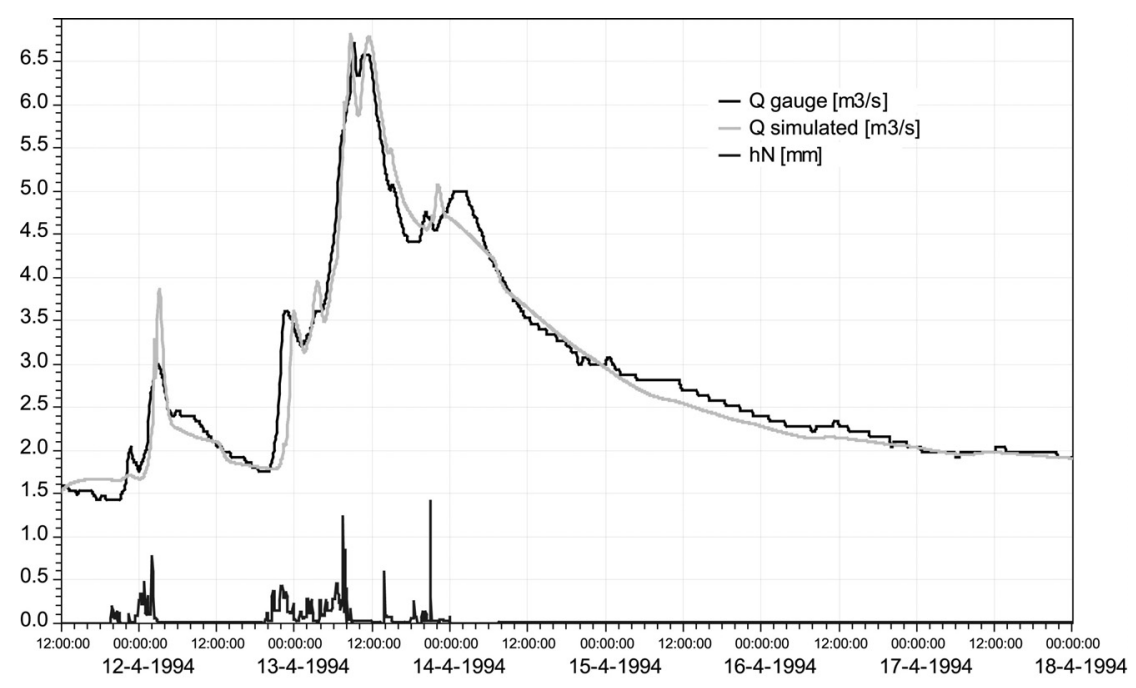

Figure 3.4 Graphical result for the calibration period.

Table 3.1 Calibration and verification results, as goodness-of-fit criteria .

\begin{tabular}{cccc}
\hline & $\begin{array}{c}\text { Correlation } \\
\text { Coefficient }\end{array}$ & $\begin{array}{c}\text { Nash-Sutcliffe } \\
\text { criterion }\end{array}$ & Mass balance error \\
\hline Calibration & 0.98 & 0.96 & $1.8 \%$ \\
Verification & 0.94 & 0.77 & $10.7 \%$ \\
\hline
\end{tabular}

\subsubsection{Model Representation of Stormwater Overflows}

Finally, the effect of areal aggregation of overflows on hydraulic stress parameters was investigated. For this purpose an urban river reach with a length of about $2.5 \mathrm{~km}$ with eleven combined sewer overflows was 
investigated. All overflows were modeled at high spatial resolution accounting for their correct geographical location. The results are given in Figure 3.5. for specific locations along the sub-system.

It is evident that the hydraulic load varies substantially along the urban river reach when individual overflow structures are considered. Principally the load increases with increasing connected urban area and consequently with the number of overflows. Beyond the urban reach natural retention processes in the river reach will dampen these effects. In contrast to this distributed model representation presented here, conventional hydrologic catchment models simulate the urban runoff in a very aggregated manner. Among other simplifying assumptions, this means that urban spills from several overflows (or a whole urban settlement) are aggregated and thus contribute to the river flow at one single grid or river segment. The new requirements of the EU-WFD, however, ask for a much more detailed analysis and assessment along the urban reach.

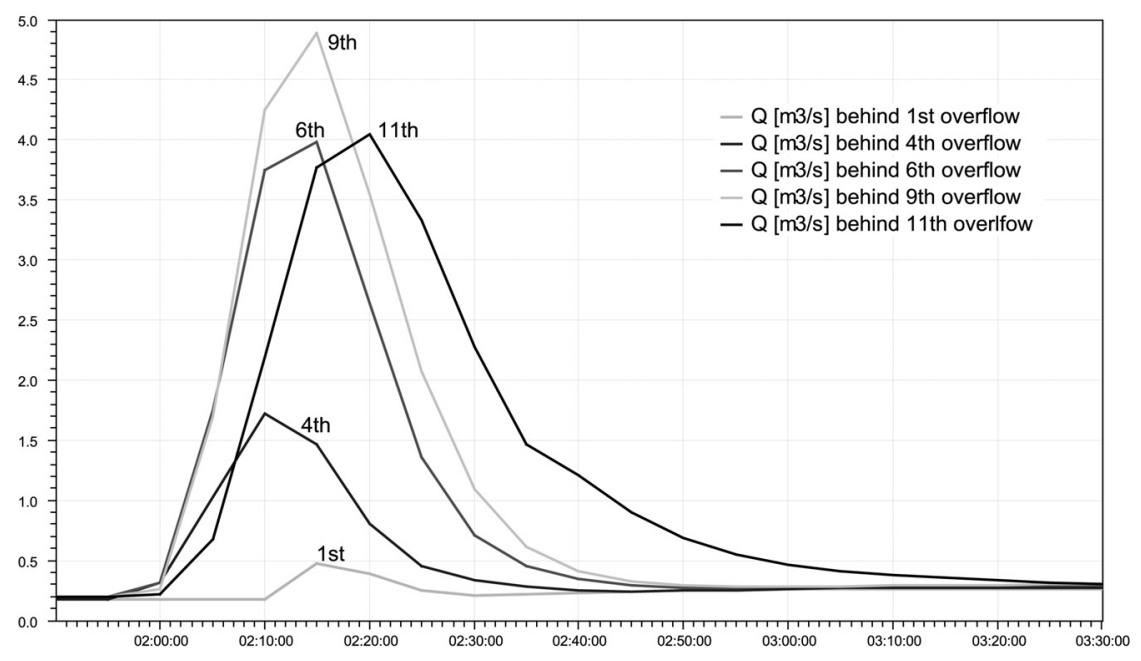

Figure 3.5 Flow propagation along a river reach in a community sub-system due to stromwater overflows (constant natural baseflow).

It was interesting to evaluate the traditional aggregation method against a detailed analysis. For this assessment, peak flows as well as their duration are suitable assessment criteria. Peak flow is now frequently used to estimate peak water level from which bottom shear stress is derived as an assessment factor for erosion and drift of organisms. The results of this comparison are 
given in Figure 3.6 for four different storm durations, with upper left having a short duration and lower right having a long duration. It is shown that for short durations aggregation leads to an overestimation of peak shear stress, while results for longer storms become increasingly similar. Additional insystem retention of combined sewer flow, however, is very cost-intensive. To avoid unnecessary investment, a detailed simulation is highly recommended.

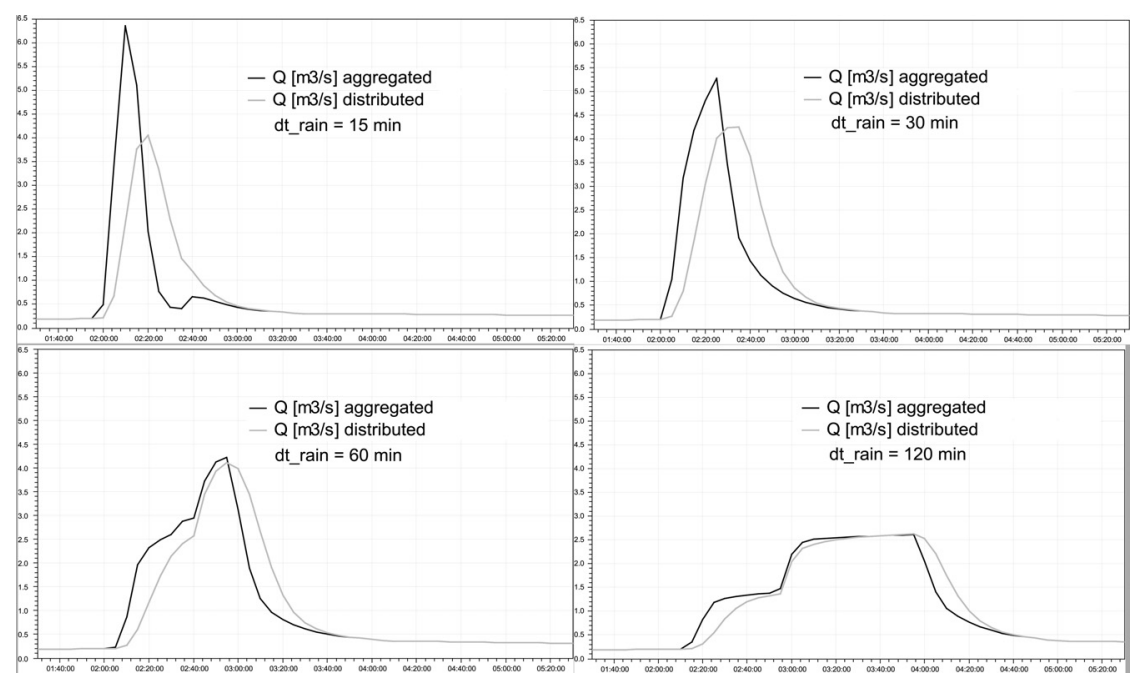

Figure 3.6 River flows for aggregated and distributed stormwater overflows.

\subsection{Conclusions}

The new European Water Framework Directives (2000) have induced further model development and integration with a focus on urban and agricultural emissions into natural streams. The authors have decided to use existing sub-models to be integrated rather than developing new models. For this purpose a physically GIS-based grid model for rural areas was coupled with a semi-distributed conceptual pollution load model for urban areas. The reasons for this decision were scientific adequacy on the one hand and practicability on the other hand. Often, highly sophisticated models cannot be applied due to missing or expensive data. In the federal state of Hesse, however, data sets for more than $90 \%$ of urban settlements have been set up 
and digital raster data are also available for topographic, land-use and soil information.

It has been proved that modeling results experienced substantial improvement after coupling, compared to measured flows. In addition, detailed modeling of urban sub-areas helps to avoid planning risk due to unnecessary aggregation of information.

\section{References}

Eastman J.R. (1999) idrisi32, GIS-Software, Clark Labs, Clark University, 950 Main Street, Worcester, MA, 01610-1477 USA, http://www.clarklabs.org

EU-WFD European Water Framework Directives (2000) Richtlinie zur Schaffung eines Ordnungsrahmens für Maßnahmen der Gemeinschaft im Bereich der Wasserpolitik, Richtlinie 2000/60/EG des Europäischen Parlaments und des Rates vom 23. Oktober, Amtsblatt der Europäischen Gemeinschaften, L327/1

Klawitter, A. (2006) Ein Modellkonzept zur integrativen Betrachtung von Urban- und Ruralhydrologie auf Einzugsgebietsebene, Mitteilungen des Instituts für Wasserbau und Wasserwirtschaft der Technischen Universität Darmstadt, Heft 138

Knauf D. (1975) Die Abflussbildung in schneebedeckten Einzugsgebieten des Mittelgebirges, PhD-Thesis, Fachbereich 13 - Wasser und Verkehr - der Technischen Hochschule Darmstadt

Lempert M. (1997) GIS gestützte Wasserbilanzsimulation. pp. 25-41 in: Berichte zur Ingenieurhydrologie und Wasserbewirtschaftung. Mitteilungen des Instituts für Wasserbau und Wasserwirtschaft, Technische Universität Darmstadt, Heft 99

Lempert M. (2000) Ein GIS gekoppeltes rasterbasiertes Modell zur Berechnung des Wasserhaushalts kleiner Einzugsgebiete, Mitteilungen des Instituts für Wasserbau und Wasserwirtschaft der Technischen Universität Darmstadt

Muschalla, D. and Ostrowski, M. (2006) Documentation of pollution load model SMUSI - Version 5.0, Fachgebiet Ingenieurhydrologie und Wasserbewirtschaftung, Technische Universität Darmstadt

O'Callaghan J.F. and Mark D.M. (1984) The extraction of Drainage Networks from Digital Elevation Data, Computer Vision, Graphics, and Image Processing 28, pp. 323-344

Ostrowski M.W. (1982) Ein Beitrag zur kontinuierlichen Simulation der Wasserbilanz, $\mathrm{PhD}$-Thesis, Mitteilungen des Institus für Wasserbau und Wasserwirtschaft der Rheinisch-Westfälischen Technischen Hochschule Aachen

Ostrowski, M., Lempert, M. Heusch, S. (2005): A mathematical model for the identification of human impacts on floods: the Modau case study, in Modelling in Natural Sciences edited by Müller and Müller, Springer-Verlag Berlin Heidelberg New York, ISBN 3-540-00153-0

Rosemann, H.-J. \& Vredal, J. (1970): Das Kalinin-Miljukov-Verfahren zur Berechnung des Ablaufs von Hochwasserwellen, Munich, Bavarian Hydrological State Service, Volume No. 6 